\title{
The intensification of dehydration process of pectin-containing raw materials
}

\author{
Igor Palamarchuk, Oksana Zozulyak, Mikhailo Mushtruk, Ievgenii Petrychenko, \\ Nataliia Slobodyanyuk, Olexander Domin, Sergiy Udodov, Olena Semenova, \\ Inna Karpovych, Roksolana Blishch
}

\begin{abstract}
The process of intensifying dehydration of pectin-containing raw materials by using centrifugation with simultaneous application of low-frequency oscillations to the working container creates an electroosmotic effect in unilateral diffusion to improve the filtration process. It is established that to reduce the technological resistance in the presented methods; it is necessary to create a fluidized bed of products due to the oscillating motion of the working capacity. An experimental vibration unit has been developed to determine the rational parameters of the vibrocentric moisture removal process using the electroosmotic effect. It is proved that the complex of the designed equipment provides consecutive carrying out of three-stage vibration filtration-convective drying of high-moisture production by an alternation of action of a stream of the heat carrier, an electromagnetic field, low-frequency fluctuations. According to the research results, the dependences of the kinetics of the moisture diffusion process on the electric field strength are obtained; frequency of electric current and duty cycle of pulses, which allowed to optimize the process parameters according to the criteria of minimizing energy consumption. It was found that the processing time to achieve the desired humidity with the application of vibration, filtration, and electroosmotic effect was twice less than for filtration drying in a fixed bed. In combination with the noted physical and mechanical factors, the proposed technology improves the technical and economic parameters of the studied process.
\end{abstract}

Keywords: vibratory-centrifugal moisture removal, electroosmotic effect, microcontroller system, drying kinetics, pectin-containing raw materials

\section{INTRODUCTION}

Pectin-containing raw material, in particular, beet pulp, which is a valuable raw material for processing, pharmaceutical, and food industries, was used as the object for processing. It is advisable to organize the production of beet pectin at sugar factories or near them [1]. One of the most promising areas of beet pulp use is dietary fiber production. Over the last decade, modern technologies have been developed to obtain clarified dietary fiber from beet pulp, which contains a large amount of pectin and can be used as an additive in manufacturing a wide range of foods. In addition, beet pulp dietary fiber has a lower moisture-holding capacity because it contains up to $10 \%$ of hydrated pectin. These properties allow using beet dietary fiber to produce dietary supplements for preventive nutrition [2].

The process of dehumidification is one of the most complex and energy-intensive one in processing and food productions. It significantly increases the cost of production. Thus, the search for innovative technology and design solutions in the drying systems development, particularly with the use of mechanical and physicomechanical processing methods [3], is becoming relevant. In modern technologies, mechanical pressing has become the most common method for removing excess moisture from the pulp-pectin raw materials. This operation is carried out mainly in screw-type machines, characterized by a reasonably high metal intensity and require significant energy consumption for their function [4].

Considering that the Fiproductivity of any mass transfer process is inversely proportional to the diffusion resistance of the medium and directly proportional to the difference in concentrations of diffusion substance compared to equilibrium, physicomechanical actions, such as providing low-frequency oscillations to the working 
container, increasing the osmotic pressure when applying an electromagnetic field in the technological environment, were used to intensify the process.

Vibrations of the working container cause both the general circulation of the loaded mass and the relative chaotic movement of the mixture components, which leads to the weakening of adhesion forces between the particles of the process medium, destruction of the formed conglomerates, changes in rheological characteristics of the material - viscosity, shear modulus, effective coefficient of friction, adhesion forces, which, taken together, create the effect of loosening the mass of the product, reducing the structural resistance and increasing the heat and mass transfer surface [5]. Electroosmotic processes in the highly humid layer of raw material, when creating a pressure difference in the working volume, allow increasing the filtration and dehumidification processes [6].

The developed drying technology was evaluated using the technical and economic parameters of the dehumidification process, namely, the minimum possible energy consumption, minimal time for reaching the given humidity, and the most effective removal of free moisture.

\section{Scientific hypothesis}

The technological hypothesis assumes a reduction of energy and material consumption due to the combination of several types of physicomechanical and technological influence, namely centrifugal, filtration, vibratory, electroosmotic; creation of the most favorable conditions for technological processing of products different in their properties due to the choice of the required type of the combined physicomechanical action on raw materials.

\section{MATERIAL AND METHODOLOGY \\ Samples}

Sugar beet pulp (Alexandria) was used as an object of processing:

- triploid hybrid;

- created by Bila Tserkva DSS together with Ivanivska research and selection station;

- high yield;

- sugar content of $19-20 \%$,

- sugar collection - 9- 10 t/ha;

- resistant to cercosporosis;

- zoned in 1997;

- recommended for growing in the areas of Polissya and Forest-Steppe.

Edible seeds of melons, particularly pumpkin, zucchini, watermelon, and melon, were purchased from farms in Vinnytsia and Kherson regions, Ukraine.

\section{Chemicals}

Chemical reagents were not used for scientific research.

\section{Biological Material}

For experimental studies, used: pumpkin seeds, grade Volga gray 92 (supplier farm Sofia, Vinnytsia region, Ukraine); zucchini seeds, Diamond variety (supplier farm Sofia, Vinnytsia region, Ukraine); watermelon seeds, Giant variety (supplier Farm Taste of Summer, Kherson region, Ukraine); melon seeds, Crenshaw variety (supplier of the Taste of Summer farm, Kherson region, Ukraine).

\section{Instruments}

Frequency converter (Mitsubishi FR-E540-075EC, producer (Inter-Synthesis) Limited Liability Company, Ukraine).

Portable vibration analyzer (AGAT-M, producer (Inter-Synthesis) Limited Liability Company, Ukraine).

Accelerometer (LIS3DH, producer (Inter-Synthesis) Limited Liability Company, Ukraine).

Tachometer (UNI-T UT372, producer (Inter-Synthesis) Limited Liability Company, Ukraine).

Autotransformer (AOSN-20-220-75, producer (Inter-Synthesis) Limited Liability Company, Ukraine).

Electronic wattmeter (EMF-1, producer (Inter-Synthesis) Limited Liability Company, Ukraine).

Moisture meter (Wile-55, producer (Inter-Synthesis) Limited Liability Company, Ukraine)

Thermometer (Infrared Thermometer IT - 100, producer (Inter-Synthesis) Limited Liability Company, Ukraine). Manual hydrometer (MS-13, producer (Inter-Synthesis) Limited Liability Company, Ukraine).

Micromanometer with an inclined tube ("MMN-240").

Stopwatch (SDSpr-1, producer (Inter-Synthesis) Limited Liability Company, Ukraine).

Technical scales (BTA-60, producer (Inter-Synthesis) Limited Liability Company, Ukraine). 


\section{Laboratory Methods}

Studies of raw material drying processes were carried out according to the general method, which involved measuring the moisture content of products depending on the processing time. Products with $60 \%$ of initial humidity were placed in the drying chamber; appropriate modes were set, particularly the temperature of the drying agent, its feed rate, amplitude, and frequency of vibrations. The feed rate of the drying agent was measured with the anemometer.

A wireless power supply sensor for recording amplitude-frequency characteristics based on STMicroelectronics' LIS3DH accelerometer was used to evaluate the energy parameters.

The UNI-T UT372 wireless tachometer was used to record the drive shaft speed.

The AOSN-20-220-75 autotransformer was used to control and change the speed of the motor shaft.

An electronic wattmeter EMF-1 was used to determine the energy characteristics of the studied machine.

Electronic laboratory technical scales BTA-60 were used to study the dewatering parameters.

The temperature of the test raw material before drying and after was measured with a certified thermometer, "Infrared Thermometer".

A manual hydrometer MS-13 is used to measure the speed of air movement in the air duct.

To measure the airflow pressure in the air duct, a multi-limit micromanometer was used with an inclined tube MMN-240 TU-25-01-277-70.

Stopwatch SDSpr-1 was used to record the drying time.

A Wile-55 moisture meter was used to control humidity.

\section{Description of the Experiment}

Sample preparation: Samples of sugar beet pulp and pumpkin, zucchini, watermelon, and melon seeds were used for the research. Samples of sugar beet pulp were collected at Gaisinsky Sugar Plant, Vinnytsia Region, Ukraine.

Number of samples analyzed: During the experimental studies, 20 different samples of sugar beet pulp and 20 samples of pumpkin seeds were examined. zucchini, watermelon, and melons, which were purchased from farms on the territory of Ukraine.

Number of repeated analyses: All measurements of an instrument, readings were performed 5 times.

Number of experiment replication: The number of repetitions of each experiment to determine one value was also 5 times.

Design of the experiment: The microcontroller system allowed obtaining information about the main parameters of the process on the personal computer display in real-time, which made it possible to optimize the processing of highly humid materials, necessary for the dynamics of heating raw materials without heating them to maximum values, i.e., the loss of biologically active substances was limited. As a result, the current measurement of seed moisture in the process of filtration moisture removal during sealing of the drying chamber due to the possibility of measuring the relative humidity of the drying agent at the inlet and outlet, when sampling is technologically impossible, was performed. When the $10 \%$ value of the product moisture content was reached, the drying process was stopped.

Experimental studies were conducted in three stages. In the first stage, the drying chamber was provided mainly with vertical oscillations using an electromagnetic vibrator. At a constant oscillation frequency of $16 \mathrm{~Hz}$, the amplitude values of 2, 4, and $6 \mathrm{~mm}$ were set, at which the duration of the filtration-convective drying process, which was carried out according to the above-mentioned method, was recorded. In the second stage of the research, the electromagnetic vibrator of horizontal oscillations was used in the previous modes, the operation of which was synchronized with the vibrator of vertical oscillations in terms of frequency and phase. In the third stage of the research, an electromagnetic vibrator of horizontal oscillations was used. With the help of an electronic electricity meter, power consumption per-process was measured, making it possible to compare specific energy consumption at different technological modes.

\section{Statistical Analysis}

The statistical evaluation of the results was carried out by standard methods using statistical software Statgraphics Centurion XVII (StatPoint, USA) - multifactor analysis of variance (MANOVA), LSD test. Statistical processing was performed in Microsoft Excel 2016 in combination with XLSTAT. Values were estimated using mean and standard deviations. 


\section{RESULTS AND DISCUSSION}

Investigation of the dehumidification process was performed following the general method, which involved measuring the moisture content of pectin-containing raw materials depending on the processing time using a laboratory installation (Figure 1). Pectin-containing raw materials with $720 \%$ initial humidity were fed through the loading device and occupied $3 / 4$ of its volume. The intensity of moisture removal was controlled by the difference in relative humidity of the drying agent at the inlet and outlet of the drying chamber. Processing was completed when the moisture of the product reached about $9-10 \%$.

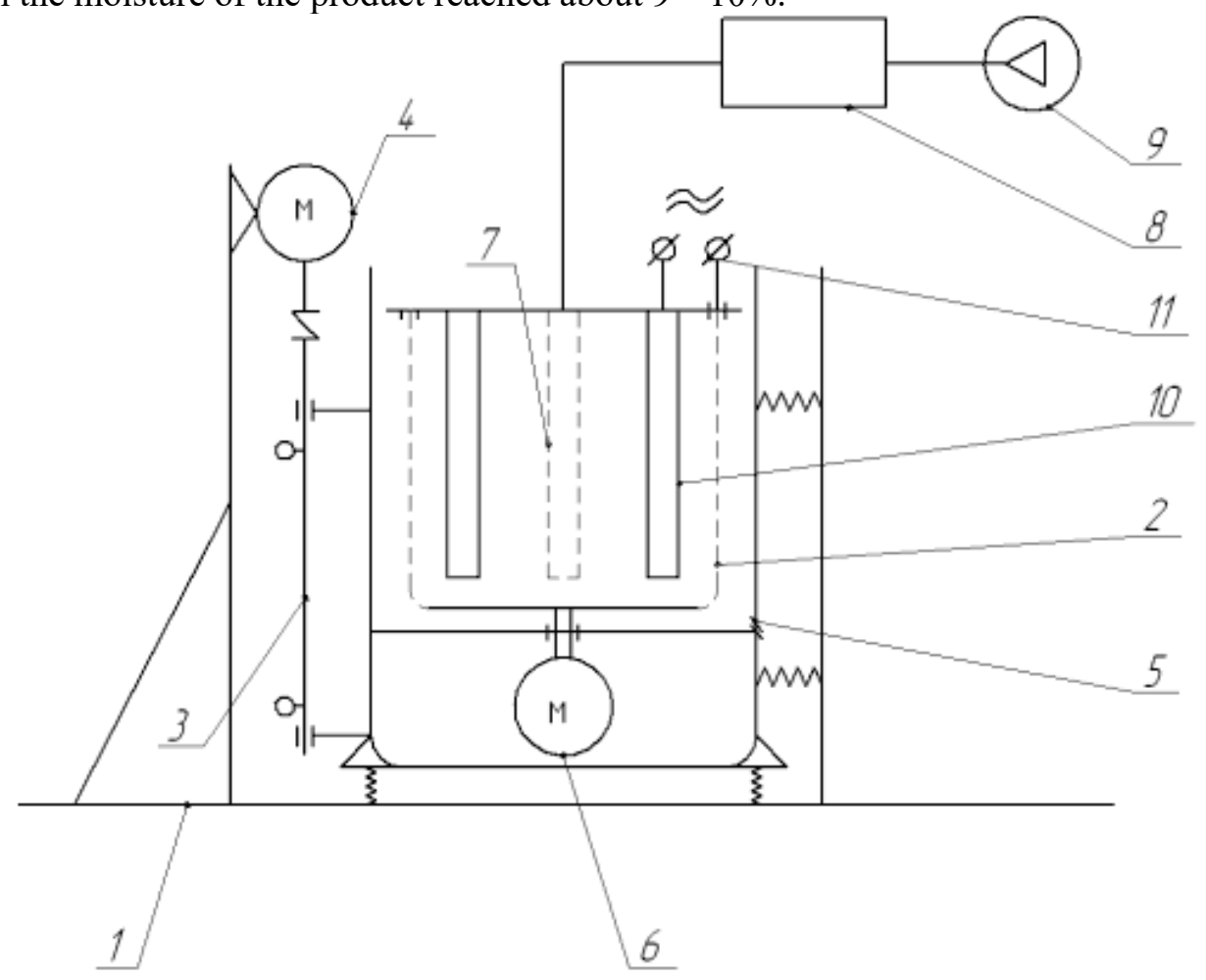

Figure 1 Vibratory centrifugal electroosmotic dehumidification.

Note: 1 - frame; 2 - perforated centrifuge rotor; 3 - vibratory drive; 4 - the electric motor of the vibratory drive; 5 - centrifuge housing; 6 - centrifuge motor; 7 - manifold; 8 - heat generator; 9 - compressor; 10 - electrodes; 11 - voltage converter.

Vibratory centrifugal electroosmotic experimental dehumidification provided a sequential three-stage filtrationconvective dehydration of highly humid raw materials by changing the technological effects and parameters. At the first stage, filtration drying in a fixed bed was studied. In a stationary drying chamber, a heated drying agent was fed through a perforated cylinder. It passed through a layer of raw used, which allowed us to trace their effect on the time of moisture removal.

The set temperature of the drying agent was maintained automatically; it was also possible to quickly adjust it with a power regulator. Frequency and amplitude of vibrations were set independently using the electronic device and by the change of the vibration exciter balance weight setting angle.

In scientific works [7], [8], [9], [10] based on experimental studies of the drying process in the vibrofluidized layer with conductive heat supply for the range of vibration frequencies from $20-80 \mathrm{~Hz}$ and amplitude from $0.0005-0.0025 \mathrm{~m}$, it was found that moisture removal occurs mainly in a period of constant drying speed, the efficiency of which is largely determined by the amplitude of oscillations at a vibration frequency of $40-60 \mathrm{~Hz}$.

According to the results of using different combinations of physic mechanical factors of intensification of the studied process, it was found that vibration-filtration drying with the use of the electroosmotic effect, depending on the kinetic characteristics of the process, appeared to be the most effective (Figure 2).

Scientific works [11], [12], [13] describe the use of electro-osmosis for dehumidification of elastic-plastic masses in combination with electrothermal treatment with alternating current allowed to establish that electricity consumption does not exceed $60-75 \mathrm{kWh} / \mathrm{m}$, efficiency compared to steam increases by $2-2.5$ times. 


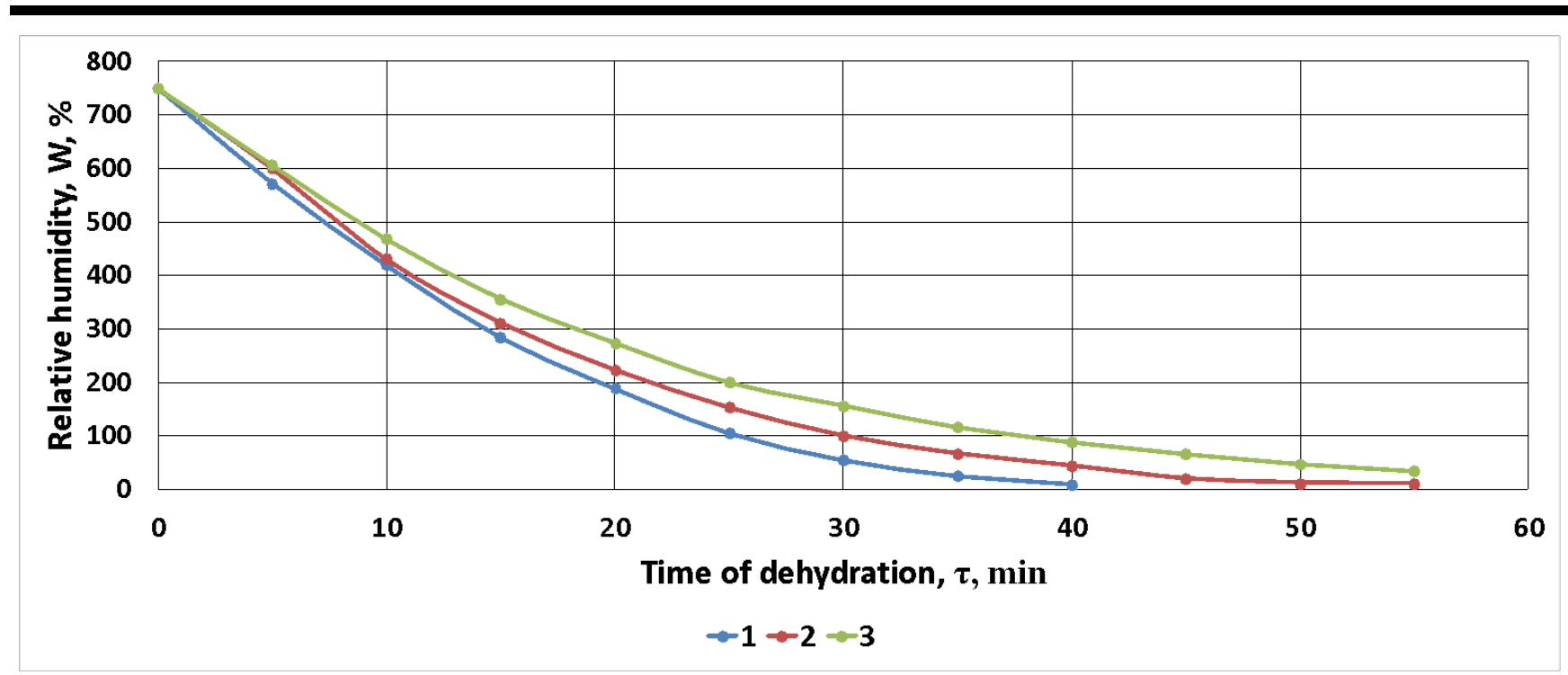

Figure 2 Kinetics of the pectin-containing raw materials drying with different methods of moisture removal.

Note: 1 - filtration drying in a fixed bed at $W n=720 \%, V=3 \mathrm{~m} / \mathrm{s} ; 2$ - vibratory filtration drying at $W n=720 \%, V=3$ $\mathrm{m} / \mathrm{s}, A=0.004 \mathrm{~m} ; 3$ - vibratory filtration drying using electro-osmotic effect at $W_{n}=720 \%, V=3 \mathrm{~m} / \mathrm{s}, A=4 \mathrm{~mm}$, $E=0.8 \mathrm{~V} / \mathrm{m}, F=200 \mathrm{~Hz}, Q=3, \Pi=0,75$.

Effective parameters of the electromagnetic field in terms of implementation of the electroosmotic effect were the following: electric field strength $E=0.8 \mathrm{~V} / \mathrm{m}$ (Figure 3); frequency of electric current $F=300 \mathrm{~Hz}$ (Figure 4); pulse relative duration $Q=3$ (Figure 5). Variation of the specified electrotechnical parameters complex at an estimation of kinetic parameters of the investigated process of the pectin-containing raw materials dehumidification allowed optimizing the process parameters according to the energy consumption minimization criteria.

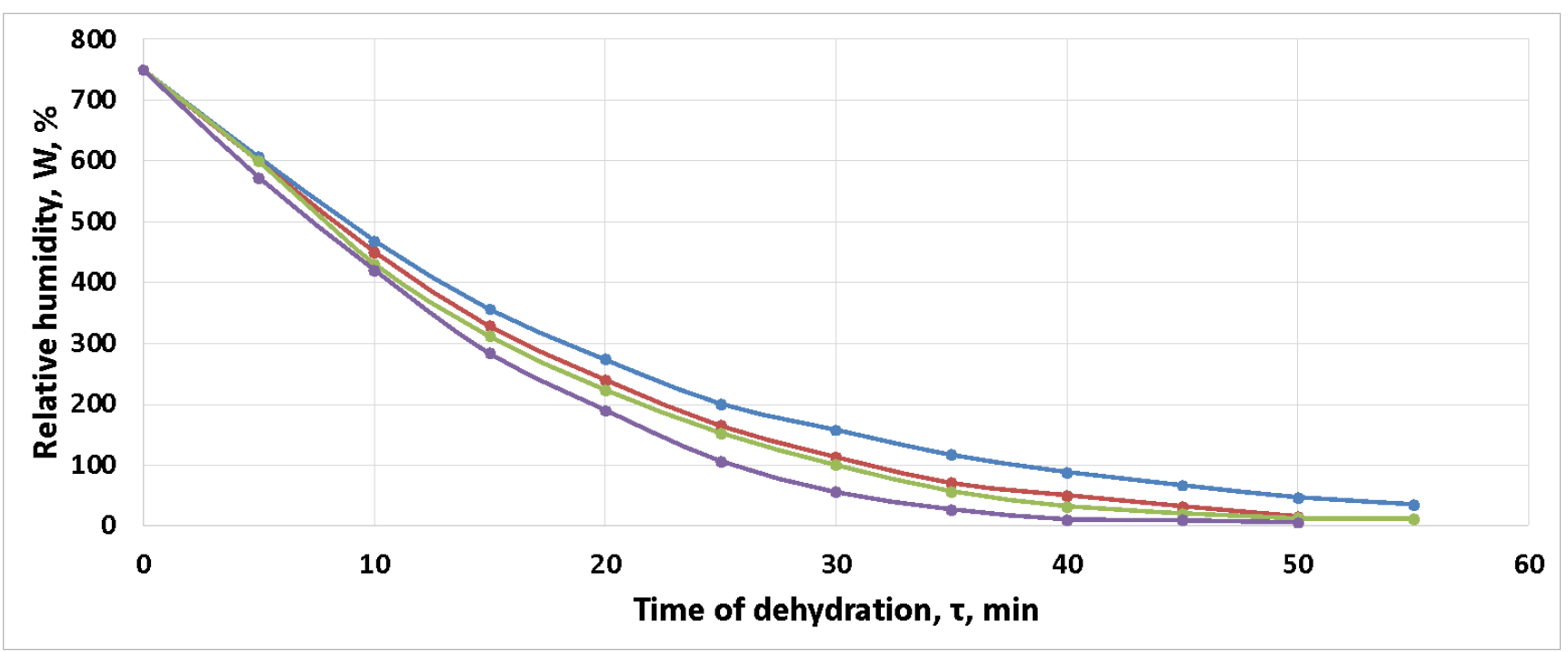

Figure 3 Effect of the electric field strength on the pectin-containing raw materials drying kinetics. Note: $W_{n}=720 \%, V=3 \mathrm{~m} / \mathrm{s}, A=0.004 \mathrm{~m} \mathrm{~mm}, F=200 \mathrm{~Hz}, Q=3, \Pi=0.75$. 


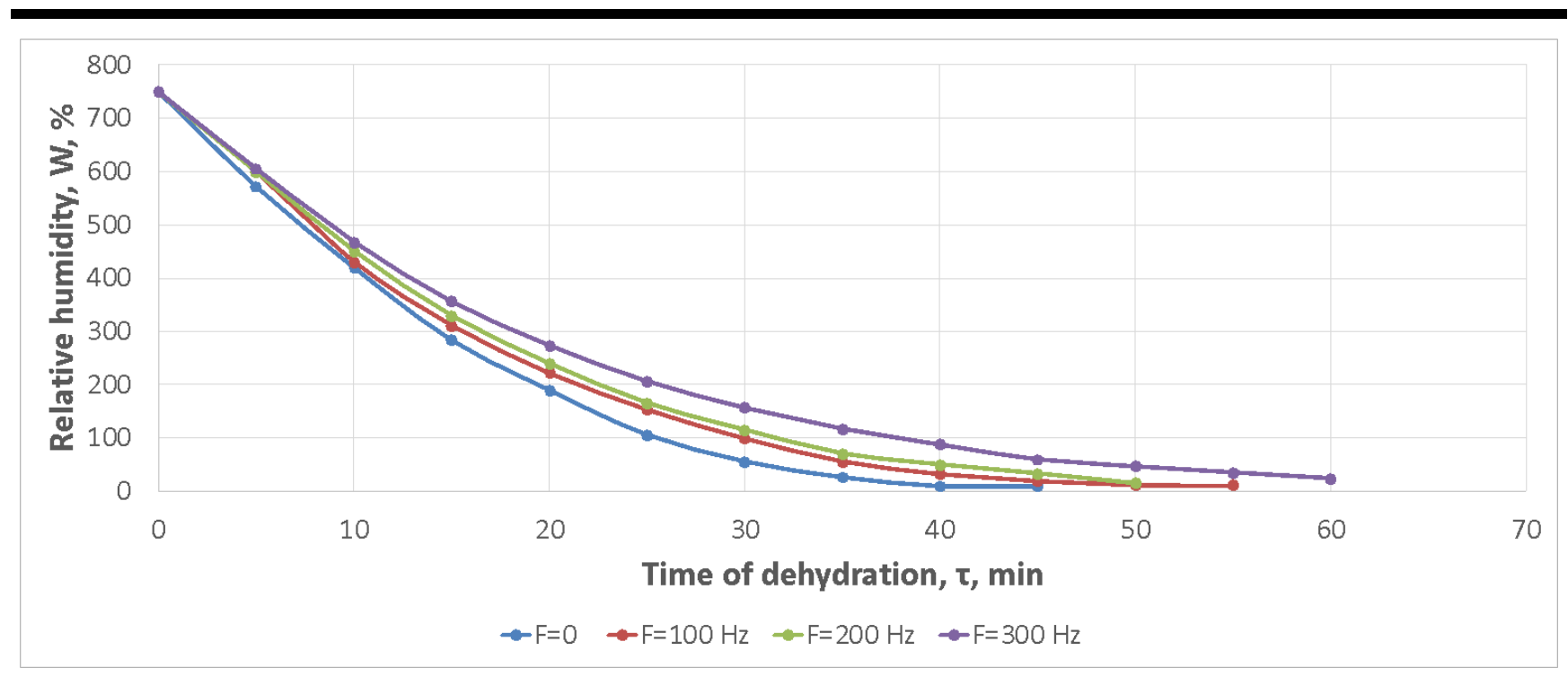

Figure 4 Influence of the frequency of electric current on the pectin-containing raw materials drying kinetics. Note: $W_{n}=720 \%, V=3 \mathrm{~m} / \mathrm{s}, A=0.004 \mathrm{~m}, E=0.8 \mathrm{~V} / \mathrm{m}, Q=3, \Pi=0.75$.

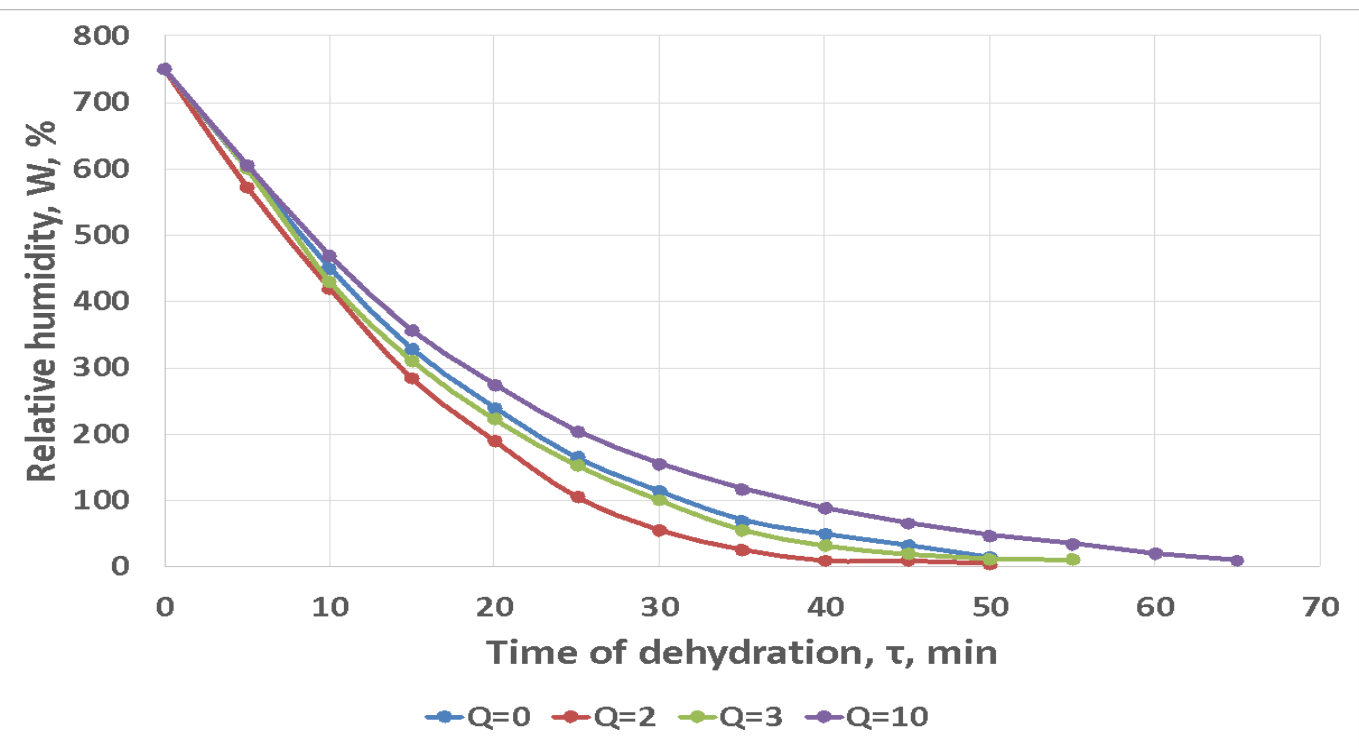

Figure 5 Influence of the pulse relative duration on the pectin-containing raw materials drying kinetic. Note: $W_{n}=720 \%, V=3 \mathrm{~m} / \mathrm{s}, A=0.004 \mathrm{~m}, E=0.8 \mathrm{~V} / \mathrm{m}, F=200 \mathrm{~Hz}, \Pi=0.75$.

As a result of centrifugal filtration of two different materials in the same conditions, different contents of the liquid phase are often found in them, which is explained by their different moisture-holding capacity [14], [15], [16], [17].

Studies of the dynamics of the heating agent flow during dehumidification (Figure 6) revealed a slight decrease in processing time with increasing convective flow rate. Given that there is a slight increase in energy consumption for the process of dehumidification, we can consider insignificant the factor of increasing the speed of the heating agent. 


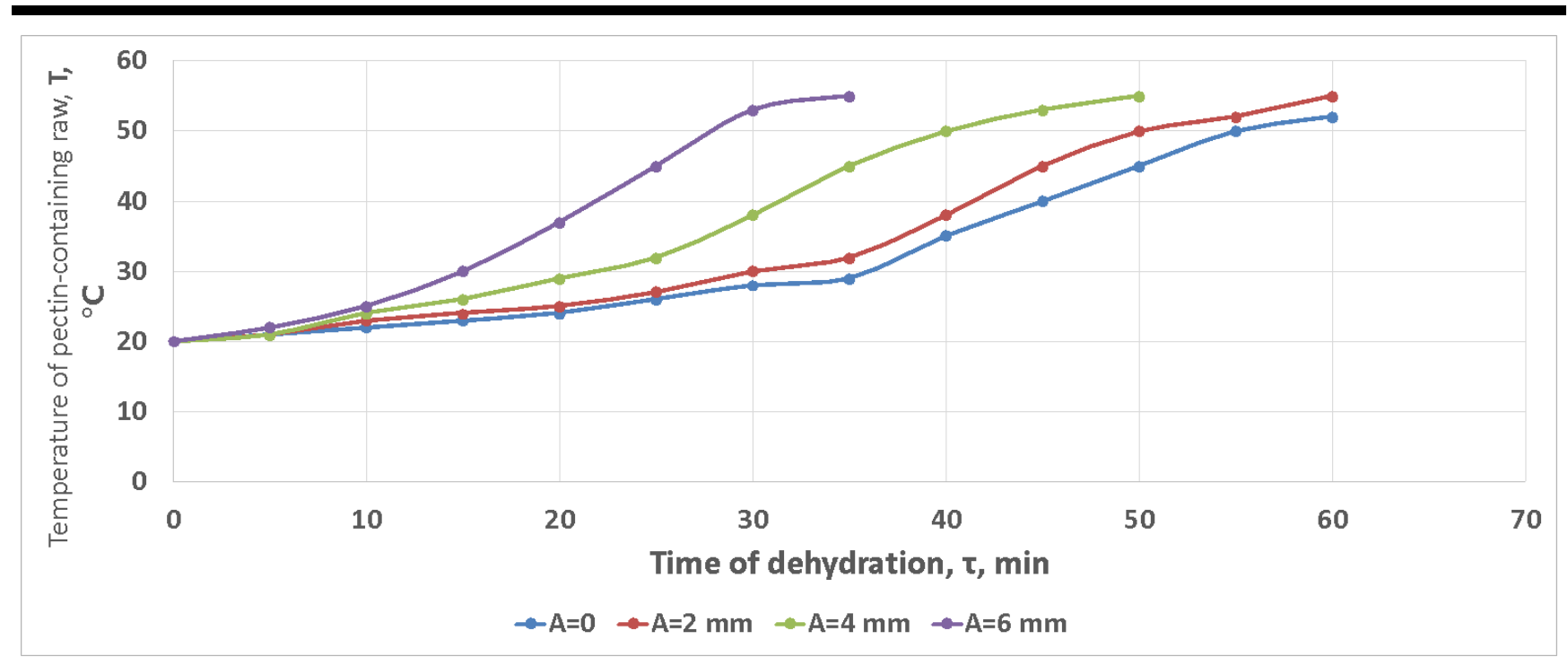

Figure 6 Dependence of the temperature of pectin-containing raw materials $T^{\circ} \mathrm{C}$ on the dehydration time $\tau$, min at different oscillations amplitudes.

When substantiating the use of a combination of physicomechanical factors for intensifying the process of the pectin-containing raw materials dehumidification, it was found that the use of vibratory filtration drying with electroosmotic effect reduces the moisture removal time by 1.44 times compared to filtration drying in a fixed bed (Figure 7 and Figure 8).

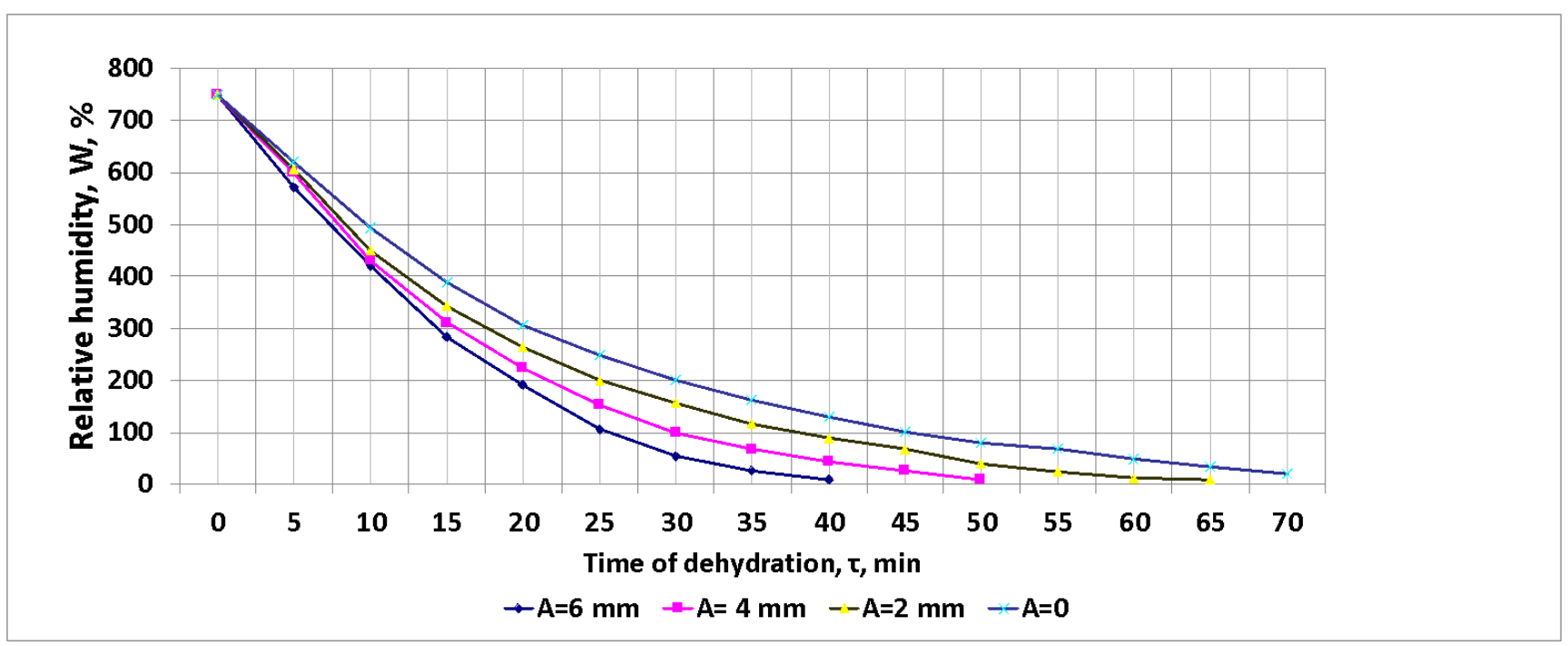

Figure 7 Dependence of the pectin-containing raw materials humidity $W, \%$ on dehydration time $\tau$, min at different oscillations amplitudes.

Note: $W_{n}=720 \%, V=3 \mathrm{~m} / \mathrm{s}, Q=3, E=0.8 \mathrm{~V} / \mathrm{m}, F=200 \mathrm{~Hz}, \Pi=0.75$.

According to the results of scientific research [18], [19], [20], it was found that the use of low-frequency oscillations in the second period of drying of beet pulp allowed to reduce the total duration of the process of heat treatment of products by $40-45 \%$. But the authors of annealing works [21]. Proved that in the conditions of the vibrofluidized layer, the total surface area of the bulk material increases, resulting in an intensive removal of moisture and an increase in the drying rate.

Reducing humidity and increasing porosity can reduce energy consumption for further drying, which can significantly speed up the process, simplify the selection and maintenance of the dryer [22], [23], [24].

The driving force of the dehumidification process is increased by vibration extrusion, centrifugation during rotor spinning, development of an electroosmotic effect when creating conditions for unilateral diffusion, and the process of filtering the medium through the perforation of the rotor. 


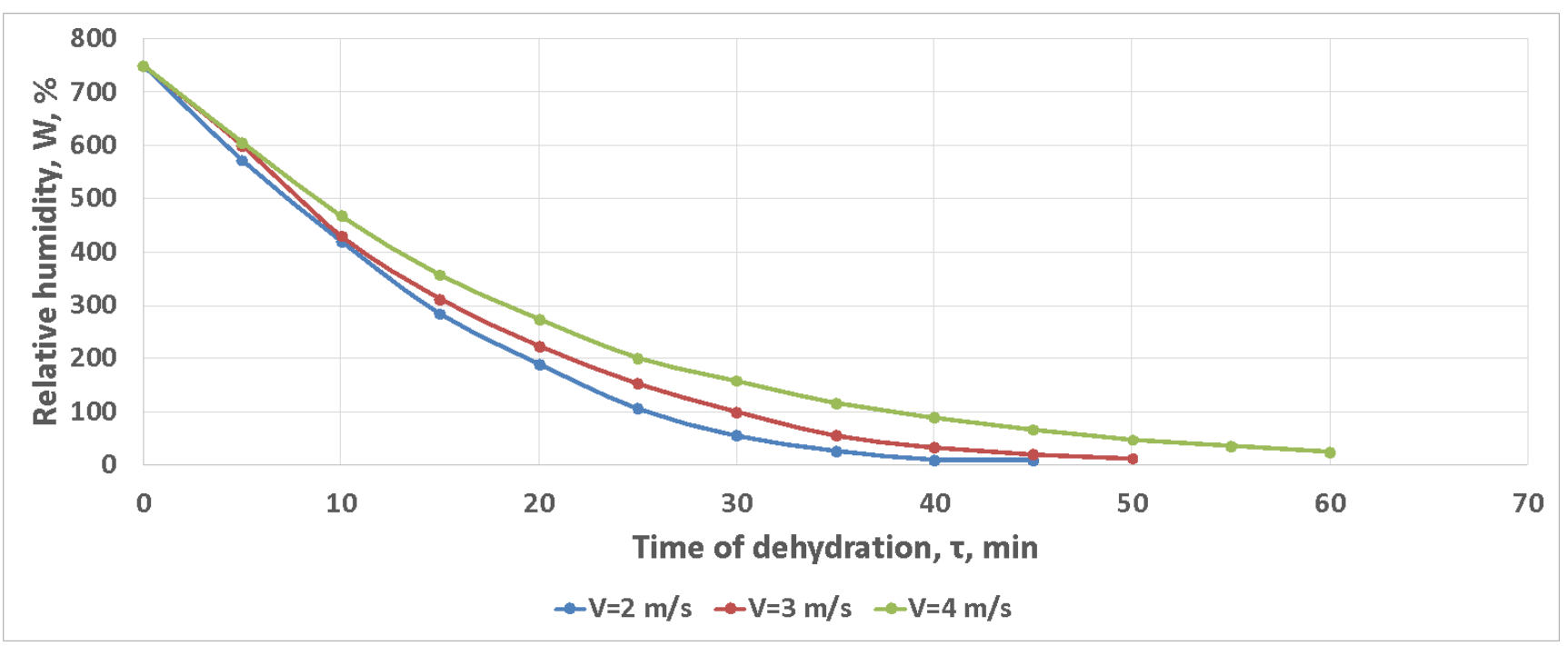

Figure 8 Dependence of the pectin-containing raw materials humidity $W, \%$ on dehydrating time $\tau$, min at different airflow rates.

Note: $W_{n}=720 \%, A=0.004 \mathrm{~mm}, Q=3, E=0.8 \mathrm{~V} / \mathrm{m}, F=200 \mathrm{~Hz}, \Pi=0.75$.

However, the latter process leads to increased technological resistance, which worsens conditions for processing intensification. This disadvantage can be offset by creating a fluidized bed of the product by providing oscillating motion to the working container, which leads to a significant reduction in the forces of internal friction in the mass of the load. Thus, the action of these factors is aimed at increasing the intensification of the dehumidification process while minimizing energy consumption.

In his research [25], [26], [27] satisfied the factors of vibration action to intensify the drying process by increasing the heat transfer process, the speed of which in different frequency modes increases from $2.5-9$ times. A combination of the above-mentioned factors allows for effective dehumidification of pectin-containing raw materials with a specific set of physicomechanical properties and certain quality restrictions of the products. This allows the formation of an effective sequence of technological influence.

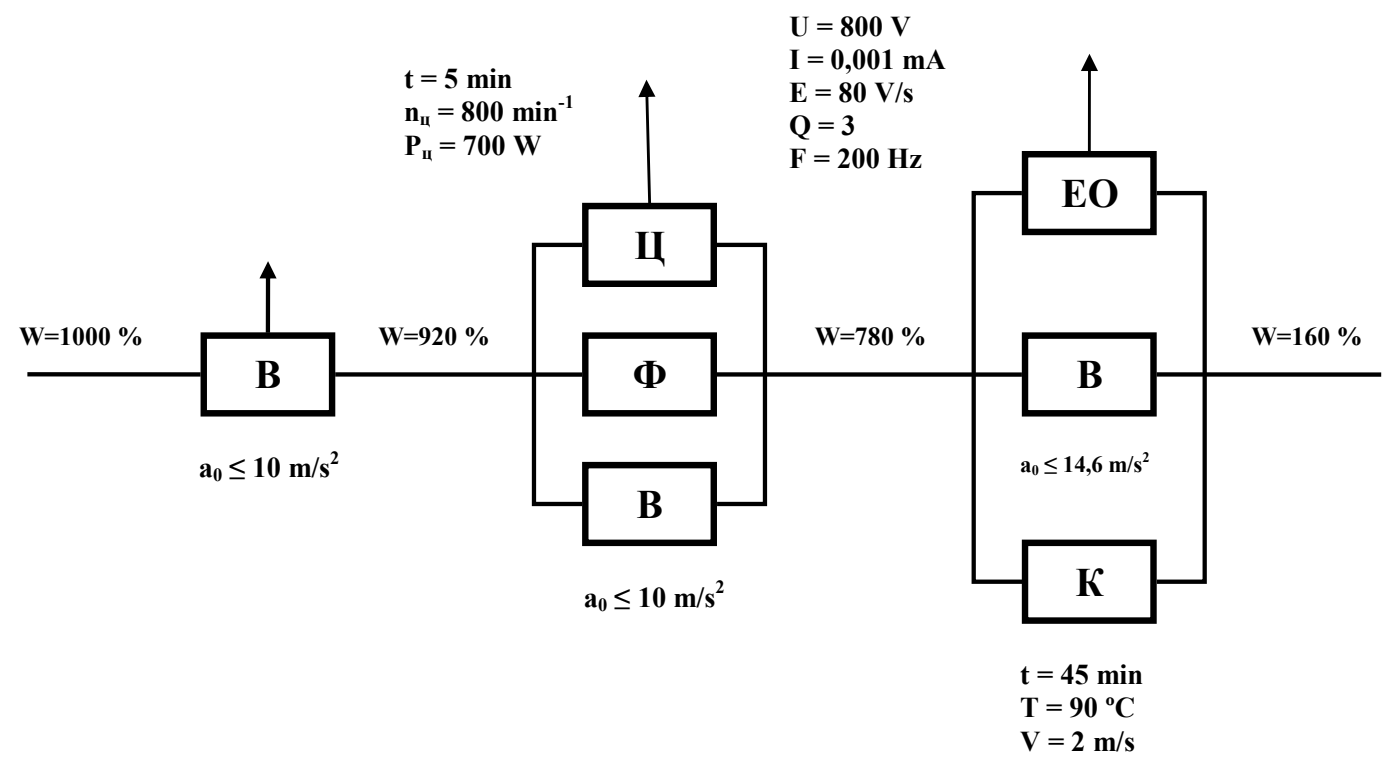

Figure 9 Scheme of the combined physicomechanical processing at implementing the modes of pectincontaining raw materials dehumidification. 
The authors of the following scientific works [28], [29], [30] proved that in the conditions of the Vibro-liquefied layer, the total surface of the bulk mass of the material increases, as a result of which there is an intensive removal of moisture and an increase in the drying rate.

The vibration of actuators, as well as blowing coolant bulk materials with low friction between particles and a slight tendency to aggregation [31], [32], [33], allow you to significantly reduce the speed of the drying agent, which reduces energy consumption for the process.

When processing the investigated pectin-containing products (Figure 9) at the 1st stage, vibration compaction is carried out to remove free moisture, which occurs due to the acceleration of the force field:

$$
a_{B} \approx g=9.81 \frac{m}{s^{2}} \text {. }
$$

At the 2nd stage of processing, free moisture is squeezed out simultaneously by centrifugation, filtration, and vibration separation. These operations are performed when reaching the resonant mode of operation of the vibrator to prevent the negative effects of vibration when resonating on the structural elements of the filter centrifuge. At the 3rd stage, operations of electroosmotic pressing, vibration loosening of technological masses are implemented, which increases the efficiency of convective drying to achieve the desired humidity of the product.

The conducted research allowed to carry out the comparative analysis of the influence of various physicomechanical measures (Figure 9) and proved the efficiency of the vibratory centrifugal removal of free moisture at the 1st stage of processing, destruction of a continuous layer of the product under the action of a vibration field at the 2 nd one and the subsequent convective diffusion with electroosmotic intensification at the 3rd stage of processing that allows reducing the energy consumption of the dehydration process by 2.7 times in comparison with traditional convective drying.

\section{CONCLUSION}

1. Taking into account the directions of the process of osmotic dehumidification improvement to determine the optimal design parameters of the equipment and mode parameters of the process, a functional diagram of a set of devices based on experimental vibration installation was developed.

2. The processing time to achieve the desired humidity when applying the vibratory, filtration, and the electroosmotic effect was twice less than filtration drying in a fixed bed.

3. The conducted research allowed determining the optimal parameters of dehumidification of thermolabile materials with the use of electroosmotic effect: electric field strength $E=0.8 \mathrm{~V} / \mathrm{m}$; electric current frequency $F=300 \mathrm{~Hz}$; pulse relative duration $Q=3$.

4. Technological scheme of electroosmotic vibration dehumidification was developed. Energy consumption for removing $1 \mathrm{~kg}$ of moisture is reduced by 2.7 times compared to traditional convective drying, given that the latter is quite destructive for thermolabile dispersed systems.

\section{REFERENCES}

1. Ballerini, M., Cabibbo, N., Candelier, R., Cavagna, A., Cisbani, E., Giardina, I., Lecomte, V., Orlandi, A., Parisi, G., Procaccini, A., Viale, M., \& Zdravkovic, V. (2008). Interaction ruling animal collective behavior depends on topological rather than metric distance: Evidence from a field study. In Proceedings of the National Academy of Sciences (Vol. 105, Issue 4, pp. 1232-1237). Proceedings of the National Academy of Sciences. https://doi.org/10.1073/pnas.0711437105

2. Stadnyk, I., Sarana, V., Mushtruk, M., Vasyliv, V., Zheplinska, M., Palamarchuk, I., Burova, Z., \& Gudzenko, M. (2021). Dynamics of interphase interaction between components during mixing. In Animal Science and Food Technology (Vol. 12, Issue 2). National University of Life and Environmental Sciences of Ukraine. https://doi.org/10.31548/animal2021.02.007

3. Barbaro, A. B. T., Taylor, K., Trethewey, P. F., Youseff, L., \& Birnir, B. (2009). Discrete and continuous models of the dynamics of pelagic fish: Application to the capelin. In Mathematics and Computers in Simulation (Vol. 79, Issue 12, pp. 3397-3414). Elsevier BV. https://doi.org/10.1016/j.matcom.2008.11.018

4. Bober, A., Liashenko, M., Protsenko, L., Slobodyanyuk, N., Matseiko, L., Yashchuk, N., Gunko, S., \& Mushtruk, M. (2020). Biochemical composition of the hops and quality of the finished beer. In Potravinarstvo Slovak Journal of Food Sciences (Vol. 14, pp. 307-317). HACCP Consulting. https://doi.org/10.5219/1311

5. Burger, M., Capasso, V., \& Morale, D. (2007). On an aggregation model with long and short-range interactions. In Nonlinear Analysis: Real World Applications (Vol. 8, Issue 3, pp. 939-958). Elsevier BV. https://doi.org/10.1016/j.nonrwa.2006.04.002

6. Palamarchuk, I., Vasyliv, V., Sarana, V., Mushtruk, M., Zheplinska, M., Burova, Z., Gudzenko, M., Filin, S., \& Omelyanov, O. (2021). Substantiation of amplitude-frequency characteristics and design parameters of vibration exciter in volume oscillation separator. In Animal Science and Food Technology (Vol. 12, Issue 

2). National University of Life
and
Environmental
Sciences of
Ukraine.

https://doi.org/10.31548/animal2021.02.006

7. Ivanova, I., Serdiuk, M., Malkina, V., Bandura, I., Kovalenko, I., Tymoshchuk, T., Tonkha, O., Tsyz, O., Mushtruk, M., \& Omelian, A. (2021). The study of soluble solids content accumulation dynamics under the influence of weather factors in the fruits of cherries. In Potravinarstvo Slovak Journal of Food Sciences (Vol. 15, pp. 350-359). HACCP Consulting. https://doi.org/10.5219/1554

8. Chuang, Y.-L., Huang, Y. R., D'Orsogna, M. R., \& Bertozzi, A. L. (2007). Multi-Vehicle Flocking: Scalability of Cooperative Control Algorithms Using Pairwise Potentials. In Proceedings 2007 IEEE International Conference on Robotics and Automation. 2007 IEEE International Conference on Robotics and Automation. IEEE. https://doi.org/10.1109/robot.2007.363661

9. Couzin, I. D., Krause, J., Franks, N. R., \& Levin, S. A. (2005). Effective leadership and decision-making in animal groups on the move. In Nature (Vol. 433, Issue 7025, pp. 513-516). Springer Science and Business Media LLC. https://doi.org/10.1038/nature03236

10. Zajác, P., Czako, P., Čapla, J., Vietoris, V., Maršálková, L., Čurlej, J., Belej, L., Golian, J., Benešová, L., \& Martišová, P. (2018). The effect of UV-C irradiation on grape juice turbidity, sensoric properties and microbial count. In Potravinarstvo (Vol. 12, Issue 1). HACCP Consulting. https://doi.org/10.5219/856

11. Degond, P., \& Motsch, S. (2008). Large Scale Dynamics of the Persistent Turning Walker Model of Fish Behavior. In Journal of Statistical Physics (Vol. 131, Issue 6, pp. 989-1021). Springer Science and Business Media LLC. https://doi.org/10.1007/s10955-008-9529-8

12. Ha, S.-Y., \& Liu, J.-G. (2009). A simple proof of the Cucker-Smale flocking dynamics and mean-field limit. In Communications in Mathematical Sciences (Vol. 7, Issue 2, pp. 297-325). International Press of Boston. https://doi.org/10.4310/cms.2009.v7.n2.a2

13. Kolyanovska, L., Palamarchuk, I., Sukhenko, Y., Mussabekova, A., Bissarinov, B., Popiel, P., Mushtruk, M., Sukhenko, V., Vasuliev, V., Semko, T., \& Tyshchenko, L. (2019). Mathematical modeling of the extraction process of oil-containing raw materials with pulsed intensification of the heat of mass transfer. In R. S. Romaniuk, A. Smolarz, \& W. Wójcik (Eds.), Optical Fibers and Their Applications 2018. SPIE. https://doi.org/10.1117/12.2522354

14. Mushtruk, M., Deviatko, O., Ulianko, S., Kanivets, N., \& Mushtruk, N. (2021). An Agro-Industrial Complex Fat-Containing Wastes Synthesis Technology in Ecological Biofuel. In Lecture Notes in Mechanical Engineering (pp. 361-370). Springer International Publishing. https://doi.org/10.1007/978-3-030-77823$1 \_36$

15. Mushtruk, M., Gudzenko, M., Palamarchuk, I., Vasyliv, V., Slobodyanyuk, N., Kuts, A., Nychyk, O., Salavor, O., \& Bober, A. (2020). Mathematical modeling of the oil extrusion process with pre-grinding of raw materials in a twin-screw extruder. In Potravinarstvo Slovak Journal of Food Sciences (Vol. 14, pp. $937-$ 944). HACCP Consulting. https://doi.org/10.5219/1436

16. Cherednichenko, O., Bal-Prylypko, L., Paska, M., \& Nikolaenko, M. (2021). The expediency of creation of technology of production of meat products of long term of storage of the combined structure. In IOP Conference Series: Earth and Environmental Science (Vol. 723, Issue 3, p. 032086). IOP Publishing. https://doi.org/10.1088/1755-1315/723/3/032086

17. Mushtruk, M., Vasyliv, V., Slobodaniuk, N., Mukoid, R., \& Deviatko, O. (2020). Improvement of the Production Technology of Liquid Biofuel from Technical Fats and Oils. In Advances in Design, Simulation and Manufacturing III (pp. 377-386). Springer International Publishing. https://doi.org/10.1007/978-3-030$\underline{50491-5 \_36}$

18. Nowak, D., \& Lewicki, P. P. (2004). Infrared drying of apple slices. In Innovative Food Science \& Emerging Technologies (Vol. 5, Issue 3, pp. 353-360). Elsevier BV. https://doi.org/10.1016/j.ifset.2004.03.003

19. Zheplinska, M., Mushtruk, M., \& Salavor, O. (2021). Cavitational Impact on Electrical Conductivity in the Beet Processing Industry. In Lecture Notes in Mechanical Engineering (pp. 755-762). Springer International Publishing. https://doi.org/10.1007/978-3-030-68014-5_73

20. Palamarchuk, I., Mushtruk, M., Sukhenko, V., Dudchenko, V., Korets, L., Litvinenko, A., Deviatko, O., Ulianko, S., \& Slobodyanyuk, N. (2020). Modelling of the process of vybromechanical activation of plant raw material hydrolysis for pectin extraction. In Potravinarstvo Slovak Journal of Food Sciences (Vol. 14, pp. 239-246). HACCP Consulting. https://doi.org/10.5219/1305

21. Palamarchuk, I., Mushtruk, M., Vasyliv, V., \& Zheplinska, M. (2019). Substantiation of regime parameters of vibrating conveyor infrared dryers. In Potravinarstvo Slovak Journal of Food Sciences (Vol. 13, Issue 1, pp. 751-758). HACCP Consulting. https://doi.org/10.5219/1184

22. Palamarchuk, I., Tsurkan, O., Palamarchuk, V., \& Kharchenko, S. (2016). Research of competitiveness vibrovolnovoy conveyor infrared dryer for postharvest processing of grain. In Eastern-European Journal of 
Enterprise Technologies (Vol. 2, Issue 7(80), p. 79). Private Company Technology Center. https://doi.org/10.15587/1729-4061.2016.65887

23. Shanina, O., Galyasnyj, I., Gavrysh, T., Dugina, K., Sukhenko, Y., Sukhenko, V., Miedviedieva, N., Mushtruk, M., Rozbytska, T., \& Slobodyanyuk, N. (2019). Development of gluten-free non-yeasted dough structure as factor of bread quality formation. In Potravinarstvo Slovak Journal of Food Sciences (Vol. 13, Issue 1, pp. 971-983). HACCP Consulting. https://doi.org/10.5219/1201

24. Smetanska, I., Tonkha, O., Patyka, T., Hunaefi, D., Mamdouh, D., Patyka, M., Bukin, A., Mushtruk, M., Slobodyanyuk, N., \& Omelian, A. (2021). The influence of yeast extract and jasmonic acid on phenolic acids content of in vitro hairy root cultures of Orthosiphon aristatus. In Potravinarstvo Slovak Journal of Food Sciences (Vol. 15, pp. 1-8). HACCP Consulting. https://doi.org/10.5219/1508

25. Sukhenko, Y., Mushtruk, M., Vasyliv, V., Sukhenko, V., \& Dudchenko, V. (2019). Production of Pumpkin Pectin Paste. In Lecture Notes in Mechanical Engineering (pp. 805-812). Springer International Publishing. https://doi.org/10.1007/978-3-030-22365-6 80

26. Sukhenko, Y., Sukhenko, V., Mushtruk, M., \& Litvinenko, A. (2018). Mathematical Model of CorrosiveMechanic Wear Materials in Technological Medium of Food Industry. In Lecture Notes in Mechanical Engineering (pp. 507-514). Springer International Publishing. https://doi.org/10.1007/978-3-319-93587$\underline{453}$

27. Zheplinska, M., Mushtruk, M., Vasyliv, V., \& Deviatko, O. (2019). Investigation of the process of production of crafted beer with spicy and aromatic raw materials. In Potravinarstvo Slovak Journal of Food Sciences (Vol. 13, Issue 1, pp. 806-814). HACCP Consulting. https://doi.org/10.5219/1183

28. Zheplinska, M., Mushtruk, M., Vasyliv, V., Sarana, V., Gudzenko, M., Slobodyanyuk, N., Kuts, A., Tkachenko, S., \& Mukoid, R. (2021). The influence of cavitation effects on the purification processes of beet sugar production juices. In Potravinarstvo Slovak Journal of Food Sciences (Vol. 15, pp. 18-25). HACCP Consulting. https://doi.org/10.5219/1494

29. Sesikashvili, O., \& Zverev, S. (2018). Heating and dehydration of grain and cereals at a combined energy supply. In Potravinarstvo (Vol. 12, Issue 1). HACCP Consulting. https://doi.org/10.5219/840

30. Vasyliv, V., Mushtruk, M., Zheplinska, M., Mukoid, R., \& Tkachenko, S. (2021). Method of Electrohydraulic Activation of Water-Lime Suspension in Sugar Production. In Lecture Notes in Mechanical Engineering (pp. 664-673). Springer International Publishing. https://doi.org/10.1007/978-3-030-913274 64

31. Donchenko, L. V., Doroshenko, T. N., Krasnoselova, E. A., Konuhova, E. V., \& Petrik, G. F. (2020). Impact of technological scheme of apple tree cultivation on fractional content of pectin substances. In IOP Conference Series: Earth and Environmental Science (Vol. 488, Issue 1, p. 012008). IOP Publishing. https://doi.org/10.1088/1755-1315/488/1/012008

32. Zh Iskakov, I., Ya Kucherenko, V., Alekseev, G. V., Kravtcova, E. V., \& Egorova, O. A. (2021). Subcritical processing of raw materials for the production of food additives. In IOP Conference Series: Earth and Environmental Science (Vol. 866, Issue 1, p. 012026). IOP Publishing. https://doi.org/10.1088/1755$\underline{1315 / 866 / 1 / 012026}$

33. Koksharov, S. A., Aleeva, S. V., \& Lepilova, O. V. (2019). Description of adsorption interactions of lead ions with functional groups of pectin-containing substances. In Journal of Molecular Liquids (Vol. 283, pp. 606-616). Elsevier BV. https://doi.org/10.1016/j.molliq.2019.03.109

\section{Funds:}

This research received no external funding.

\section{Acknowledgments:}

We would like to thank you to Dr. for Larysa Bal-Prylypko.

\section{Conflict of Interest:}

The authors declare no conflict of interest.

\section{Ethical Statement:}

This article does not contain any studies that would require an ethical statement. 


\section{Contact Address:}

Igor Palamarchuk, National University of Life and Environmental Sciences of Ukraine, Faculty of Food Technology and Quality Control of Agricultural Products, Department of Processes and Equipment for Processing of Agricultural Production, Heroes of Defense Str., 12 B, Kyiv, 03040, Ukraine,

E-mail: vibroprocessing@gmail.com

ORCID: https://orcid.org/0000-0002-0441-6586

Oksana Zozulyak, National University of Life and Environmental Sciences of Ukraine, Faculty of Food Technology and Quality Management of Agricultural Products, Department of Technologies of Meat, Fish and Marine Products, Polkovnika Potekhina, Str.16, 03041 Kyiv, Ukraine,

E-mail: ksuxazoz1980@gmail.com

ORCID: https://orcid.org/0000-0002-5024-4551

*Mikhailo Mushtruk, National University of Life and Environmental Sciences of Ukraine, Faculty of Food Technology and Quality Control of Agricultural Products, Department of Processes and Equipment for Processing of Agricultural Production, Heroes of Defense Str., 12 B, Kyiv, 03040, Ukraine,

E-mail: mixej.1984@ukr.net

ORCID: https://orcid.org/0000-0002-3646-1226

Ievgenii Petrychenko, Uman National University of Horticulture, Department of Agroengineering, Institutska St., 1, 20300 Uman, Ukraine, Tel.: +38(096) 949-21-64,

E-mail: 22102210g@ukr.net

ORCID: https://orcid.org/0000-0003-1037-077X

Nataliia Slobodyanyuk, National University of Life and Environmental Sciences of Ukraine, Faculty of Food Technology and Quality Control of Agricultural Products Department of technology of meat, fish and marine products, Polkovnyka Potiekhina Str., 16, Kyiv, 03040, Ukraine,

E-mail: slob2210@ukr.net

ORCID: https://orcid.org/0000-0002-7724-2919

Olexander Domin, National University of Life and Environmental Sciences of Ukraine, Mechanical and Technological Faculty, Department of Transport Technologies and Means of Agro-Industrial Complex, Heroes of Defense Str., 12 B, Kyiv, 03040, Ukraine,

E -mail: domin31@gmail.com

ORCID: https://orcid.org/0000-0002-3907-0992

Sergiy Udodov, National University of Food Technologies, Department of Machines and Apparatuses for Food and Pharmaceutical Productions, Volodymyrska Str. 68, 01601 Kyiv, Ukraine,

E -mail: kiypivo@gmail.com

ORCID: https://orcid.org/0000-0001-6149-9974

Olena Semenova, National University Food Technologies, Department of Environmental Safety, Volodymyrska Str. 68, 01601 Kyiv, Ukraine,

E-mail: tata $\mathrm{t} @, 2008$ ukr.net

ORCID: https://orcid.org/0000-0002-9566-0022

Inna Karpovych, National University of Food Technologies, Department of Sugar Technology and Water Preparation, Volodymyrska Str. 68, 01601 Kyiv, Ukraine,

E-mail: inkarp@ukr.net

ORCID: https://orcid.org/0000-0002-5912-7466

Roksolana Blishch, Lviv Polytechnik National Unisversity, Department of Organic Products Technology, St. George's Square, 2, 79013 Lviv, Ukraine,

E-mail: roksolanaalex1976@gmail.com

ORCID: https://orcid.org/0000-0003-1143-5264

Corresponding author: *

(C) 2022 Authors. Published by HACCP Consulting in www.potravinarstvo.com the official website of the Potravinarstvo Slovak Journal of Food Sciences, owned and operated by the Association HACCP Consulting, Slovakia, www.haccp.sk. The publisher cooperate with the SLP London, UK, www.slplondon.org the scientific literature publisher. This is an Open Access article distributed under the terms of the Creative Commons Attribution License https://creativecommons.org/licenses/by/4.0, which permits unrestricted use, distribution, and reproduction in any medium provided the original work is properly cited. 